This is the author's Post-print version (final draft post-refereeing as accepted for publication by the journal). The definitive, peer-reviewed and edited version of this article is published as: van Ham M. and Clark W.A.V (2009) Neighbourhood mobility in context: household moves and changing neighbourhoods in the Netherlands. Environment and Planning A 41, 1442-1459. http://dx.doi.org/10.1068/a4182

\title{
Neighbourhood mobility in context: household moves and changing neighbourhoods in the Netherlands ${ }^{1}$
}

\author{
Maarten van Ham*, William A.V. Clark ${ }^{* *}$ \\ *University of St Andrews, School of Geography \& Geosciences, Irvine Building, North \\ Street, St Andrews, Fife, KY16 9AL, UK. Phone +44 (0)1334 463912, Fax +44 (0)1334 \\ 463949. E-mail: maarten.vanham@st-andrews.ac.uk \\ *** Department of Geography, University of California, Los Angeles, Los Angeles, CA \\ 90095-1524, USA. Email: wclark@ geog.ucla.edu
}

\begin{abstract}
Although high levels of population mobility are often viewed as a problem at the neighbourhood level we know relatively little about what makes some neighbourhoods more mobile than others. The main question in this paper is to what extent differences in out-mobility between neighbourhoods can be explained by differences in the share of mobile residents, or whether other neighbourhood characteristics also play a role. To answer this question we focus on the effects of the socio-economic status and ethnic composition of neighbourhoods and on neighbourhood change. Using data from the Netherlands population registration system and the Housing Demand Survey we model population mobility at both individual and neighbourhood levels. The aggregate results show that the composition of the housing stock and the neighbourhood population explain most of the variation in levels of neighbourhood out-mobility. At the same time although ethnic minority groups in the Netherlands are shown to be relatively immobile, neighbourhoods with concentrations of ethnic minorities have the highest population turnover. The individual level models show that people living in neighbourhoods, with an increase in the percentage of ethnic minorities are more likely to move, except when they belong to an ethnic minority group themselves. The evidence suggests that "white flight" and "socio-economic flight" are important factors in neighbourhood change.
\end{abstract}

Key words: neighbourhoods; population turnover; socio-economic status; ethnic minorities; neighbourhood change, racial proxy hypothesis

\section{INTRODUCTION}

Rapid population turnover in a neighbourhood is often associated with a range of negative outcomes at the individual level. Research has established correlations between high population turnover and residents' involvement in violence and crime (Shaw and McKay, 1969; Sampson et al., 1997) and there is some evidence that residential

\footnotetext{
${ }^{1}$ This paper was originally formulated with Frans Dieleman before his untimely death three years ago. We wish to acknowledge his ideas and concepts which have been incorporated into the paper as we developed it and to dedicate the paper to the memory of his work on urban patterns and processes.
} 
instability is related to the health of residents (Aneshensel and Sucoff, 1996; Drukker et al., 2005). A high level of population turnover is seen as both a symptom and a cause of problems at the neighbourhood level (Page, 1993; Power and Tunstall, 1995; Pawson and Bramley, 2000; Anderson and Bråmå, 2004). High population turnover is thought to be associated with neighbourhood deprivation, levels of crime, weak social structures within neighbourhoods, a lack of identification with the neighbourhood and anonymity (Pawson and Bramley, 2000; Parkes and Kearns, 2003). High population turnover can also cause a spiral of decline, further weakening social structures, resulting in an even higher population turnover, and reinforcing the negative cycle (Social Exclusion Unit, 2001, Anderson and Bråmå, 2004). Often, it is not the level of mobility, but the selective character of the mobility that causes problems, especially when there is an exodus of the better off and an inflow of low socio-economic groups, driving the neighbourhood towards decline (Friedrichs, 1991; Power, 1997; Skifter Andersen, 2002; Anderson and Bråmå, 2004).

There are many assumptions about the relationship between neighbourhood socio-economic status and the level of population turnover in neighbourhoods (see Bailey and Livingston, 2007 for a discussion). But we actually do not know a great deal about the interaction between neighbourhood characteristics and neighbourhood population mobility. The scarce literature explicitly focussing on understanding neighbourhood level mobility suggests that it is not the socio-economic status of neighbourhoods, but the demographic mix of the neighbourhood population and characteristics of the housing stock that are the main explanations of neighbourhood population mobility (for the USA see Moore and Clark, 1990; for the UK see Bailey and Livingston, 2007). The aim of this paper is to increase our understanding of the variation in out-mobility between neighbourhoods. We are interested in out-mobility because those who leave a neighbourhood have a potentially large effect on neighbourhood change when replaced by others with different characteristics.

On the individual level, there is increasing empirical evidence that characteristics of the residential context play a role in explaining moving behaviour (Galster, 1987; Clark et al., 2006; Van Ham and Feijten 2008). Both the socio-economic status of neighbourhoods (Harris, 1999) and the ethnic mix of the neighbourhood population (Clark, 1992; Crowder, 2000) have been linked to residential mobility. Some would argue that static characteristics of the neighbourhood can not influence neighbourhood mobility as people choose a neighbourhood knowing its characteristics. Instead, research should focus on the effect of (unanticipated) changes in the neighbourhood as determinants of mobility behaviour (see Galster, 1987; Lee et al., 1994; Feijten and Van Ham, 2008). We do, however, think there are also good reasons to believe that static neighbourhood characteristics can influence mobility. First, due to imperfect information upon arrival in a neighbourhood, negative aspects of a neighbourhood might only reveal themselves after some length of time. Second, people's needs and desires change over time, which might have an effect on how people see their neighbourhood. Third, not all people end up in the neighbourhood of their choice. For most people a suitable dwelling will be the first priority, which will be accepted even when the dwelling is located in a less desirable neighbourhood. Forth, the choice to live in a highly mobile or deprived neighbourhood can be a positive choice connected with a certain phase in the life-course and people might expect to soon move out of the neighbourhood soon again.

The main question in this paper is to what extent differences in out-mobility between neighbourhoods can be explained by differences in the share of mobile residents, or whether other neighbourhood characteristics also play a role. We will focus explicitly on the effects of the socio-economic status of neighbourhoods, the ethnic composition of the population and on neighbourhood change. Using secondary data from the Netherlands population registration system (GBA) and the Housing Demand 
Survey (WBO) we model population mobility at both neighbourhood and individual levels.

\section{LITERATURE REVIEW}

Most residential mobility is driven by a mismatch between a household's residential needs and preferences on the one hand and the characteristics of its current housing situation on the other hand (Brown and Moore, 1970; Speare et al., 1975; Quigley and Weinberg, 1977; Clark and Dieleman, 1996). This mismatch is often the result of demographic changes in the household that lead to the need for more (or less) space (Clark and Dieleman, 1996). Age and household composition are among the most important predictors of general residential mobility (Mulder, 1993). Singles and couples without children are known to be more mobile than couples with children, mainly because they are more likely to have few commitments, to have not yet settled and to be working on their labour market trajectory. Income (and indirectly level of education) is also thought to be an important factor in understanding housing careers (Clark et al., 2006). Those who live in crowded accommodation are most likely to move (Landsdale and Guest, 1985; Clark and Dieleman, 1996). Further, homeowners and those living in single-family dwellings are known to be the least likely to move (Clark and Dieleman, 1996; Helderman et al., 2004).

Given the above, and in line with theory (e.g. Quigley and Weinberg, 1977) and what was found by Bailey and Livingston for the UK (2007), we expect that the composition of the neighbourhood housing stock and the associated population sorted into the stock will be the most important predictors of variation in mobility between neighbourhoods. Neighbourhoods with a large percentage of rented dwellings and many young singles can be expected to show the highest population mobility. Levels of mobility can also be expected to be influenced by the supply side of the housing market. Mobility is likely to be highest in housing markets with many opportunities for households to find a dwelling that suits their housing needs.

There is increasing evidence that neighbourhood characteristics - beyond simple compositional effects - are also part of the explanation of residential mobility (Lee et al., 1994; Parkes and Kearns, 2003; Clark et al., 2006; Van Ham and Feijten, 2008; Feijten and Van Ham, 2008). For example, Kearns and Parkes (2003), using UK data from the English House Condition Survey, found that perceived neighbourhood decline increases the probability that people wish to move, but decreased the probability that they would actually move. They also found people who are unhappy with disorder in the immediate surroundings of their dwelling to be more likely to move, although they did not find an effect on moving behaviour of characteristics of the wider neighbourhood. The literature distinguishes two sets of neighbourhood characteristics potentially influencing population mobility: the physical structure of the neighbourhood and socio-economic and ethnic characteristics of the neighbourhood population (Amérigo, 2002). An important characteristic of the physical dimension is building density, which is a good proxy for such factors as (noise) pollution, (lack of) green public space, infrastructure, and the appearance of the built environment. Evidence from the USA and Europe consistently shows that people prefer to live in low-density environments. Only a small part of the population has a strong preference for living in the highly-urbanized core areas of large cities (Brower, 1996; Brun and Fagnani, 1994; Talen, 2001). In the remainder of this literature review we will focus on the socioeconomic and ethnic characteristics of the neighbourhood population as an explanation of population mobility. 
There is strong academic and policy interest in peoples ability to escape poor neighbourhoods (e.g. for the Netherlands see Bolt and Van Kempen, 2003, for the US see Quillian, 1999; 2003). In general, when given the opportunity, people exhibit a tendency to move away from neighbourhoods with low socio-economic status. Using data from the American Panel Study of Income Dynamics Quillian (1999, 2003) showed that the non-poor move away from poor neighbourhoods and that African Americans are less successful than whites in leaving poor neighbourhoods even after controlling for their poverty status. Research has shown a range of (negative) contextual effects of poor neighbourhoods on residents' social position and social opportunities such as on school dropout rates (Overman, 2002); childhood achievement (Duncan et al., 1994); transition rates from welfare to work (Van der Klaauw and Ours, 2003); deviant behaviour (Friedrichs and Blasius, 2003); social exclusion (Buck, 2001); and social mobility (Musterd et al., 2003). According to a literature review by Harris (1999), households (especially those with children) attempt to avoid neighbourhoods with low socio-economic status, and neighbours who deviate from mainstream norms and values. Low income, unemployment and low levels of education are seen as indicators of such deviance (Auletta, 1982; Wilson, 1987; Katz, 1989). From the above it follows that we can expect that neighbourhoods with low socio-economic status will show high levels of population mobility.

As stated in the introduction, some argue that it is not neighbourhood socioeconomic status per se that influence residential mobility behaviour, but (unanticipated) change in neighbourhood status. People select themselves into neighbourhoods based on the choice for a certain dwelling in a certain neighbourhood, and they tend to stay other things being equal. Once people have selected a neighbourhood, they become attached to them (Aitken, 1990). When the socio-economic status of a neighbourhood changes, especially to a less desirable status, higher status residents can be expected to have high probabilities of moving out. Their replacements are likely to be less affluent families, which in turn may bring poverty, unemployment and associated problems to the neighbourhood, creating a spiral of selective downward mobility associated with high levels of population turnover.

\section{Neighbourhood ethnic composition}

The debate on the role of the neighbourhood socio-economic status in understanding selective residential mobility is closely related to the debate on the role of ethnic composition of the neighbourhood population (Clark, 2007). Two main explanatory mechanisms through which the ethnic composition of neighbourhoods influences mobility have been suggested. The 'racial proxy hypothesis' argues that a whole range of social problems are concentrated in neighbourhoods with a high percentage of ethnic minorities (Taub et al., 1984; Clark, 1992; Harris, 1999). This is partly because some ethnic minority groups are more likely to be unemployed and poor, and partly because ethnic minorities often end up in poor, deprived and unstable neighbourhoods as a result of limited choice on the housing market (Bolt and Van Kempen, 2003). According to the racial proxy hypothesis, people want to escape ethnic concentration neighbourhoods because these neighbourhoods are deprived and not because they have an aversion to living near minority group members per se (Crowder, 2000). In a similar fashion, an increase in ethnic minorities in a neighbourhood can function as a proxy for an increase of a range of problems in the neighbourhood. According to Gould Ellen (2000), households in the USA tend to associate a growing ethnic minority presence in a neighbourhood with structural decline which therefore can be a reason to leave the neighbourhood. Harris (1999) states that if models properly control for ethnic composition and (change in) socio-economic composition, neighbourhood desirability should not be affected by ethnic composition, or change in ethnic composition. It is therefore very important that neighbourhood ethnic composition and non-ethnic socioeconomic neighbourhood characteristics are analyzed together (Harris, 1999). 
An alternative mechanism which is invoked to explain neighbourhood population mobility is the differing choices of white and other ethnic groups for the preferred composition of the neighbourhood. Initially postulated by Schelling (1969, 1971) different ethnic groups live in different neighbourhoods because of their varying preferences for own and other race combinations. With consequent moving behaviour individuals of one race or ethnicity cumulatively settle in highly segregated neighbourhoods. Clark's empirical examination of the Schelling hypothesis for the USA (1991) confirmed that the thesis is broadly correct, but that the differences in neighbourhood preferences between blacks and whites are significantly greater than those postulated by Schelling (see also other studies such as Clark, 1992; Ihlanfeldt and Scafidi, 2002; Ioannides and Zabel, 2003; Zorlu and Mulder, 2008). Based on Schelling $(1969,1971)$ we can expect that an increase in the percentage of ethnic minorities in the neighbourhood especially affects the probability of out-mobility of the native Dutch population.

Some studies while conceding that preferences play a role in neighbourhood choice, argue that prejudice and discriminatory reaction also play a role in the levels of neighbourhood change in ethnicity (Bobo and Zubrinsky, 1996). The white flight literature (Crowder, 2000) often suggests that whites leave their neighbourhood because of the increase in the share of ethnic minorities in the neighbourhood. Other support for the idea that recent changes in the ethnic composition of neighbourhoods have an effect on whites' mobility decisions comes from several studies of neighbourhood transitions (Wolf, 1963; Rapkin and Grigsby, 1960; Taub et al., 1984). In the Netherlands, neighbourhoods with high concentrations of ethnic minorities are generally perceived as less desirable compared to 'white' neighbourhoods (Bolt et al., 2008). Although levels of ethnic segregation and concentration are kept to a relatively low level by a broad set of welfare state arrangements, there are still relatively large differences between neighbourhoods.

\section{Hypotheses}

The following hypotheses have been derived from the literature and will be tested in the empirical section of this paper:

1. Neighbourhoods with a high percentage of ethnic minorities have high population mobility and people living in neighbourhoods with a high percentage of ethnic minorities have a higher probability of moving than people who live in a neighbourhood with a low percentage of ethnic minorities.

2. Neighbourhoods which experience an increase in the percentage of ethnic minorities have high population mobility and people living in a neighbourhood which experienced an increase in the percentage of ethnic minorities are more likely to move than those in stable neighbourhoods.

3. Neighbourhoods with a high socio-economic status have low population mobility and people living in neighbourhoods with a high socio-economic status have a lower probability of moving than people who live in a neighbourhood with a low socioeconomic status.

4. Neighbourhoods which experience a drop in socio-economic status have high population mobility and people living in a neighbourhood which experienced a drop in socio-economic status are more likely to move than those in stable neighbourhoods.

5. An increase in the percentage of ethnic minorities in a neighbourhood is expected to mainly affect the probability of out-mobility of those belonging to the native Dutch population. Following the same reasoning that people want to live among people similar to themselves we expect that a drop in socio-economic status of the neighbourhood mainly influences the probability of out-mobility of those with a high income. 
6. Based on the 'racial proxy hypothesis' we expect that controlling for (change in) the socio-economic status of neighbourhoods will result in insignificant effects for the neighbourhood ethnicity variables.

\section{DATA AND METHOD}

We obtained data on population mobility on the 4-digit postcode level for the year 2002 from Statistics Netherlands (CBS). The registration data originates from the Netherlands Municipal Personal Records Database (GBA). There is no one-to-one relationship between 4-digit postcode areas and neighbourhoods as perceived by residents (see Galster, 2001). However, in urban areas, 4-digit postcodes come close to what people may perceive as their neighbourhood as urban neighbourhoods are relatively small in size (one square kilometre or less). To stay as close as possible to the concept of a neighbourhood, we excluded all rural postcodes and postcodes with less than 100 inhabitants (mainly industrial areas), leaving 2,604 useable postcodes.

We used 9 postcode level variables from the ABF Combimonitor: percentage of owner occupied dwellings (ABF Research-SysWov); percentage of population aged 1534 and aged 65-84 (CBS-Population statistics); percentage households with children (CBS-Population statistics); percentage one-person households (CBS-Population statistics); percentage dwellings built after 1991 (ABF Research-SysWov); percentage of non-western migrants (CBS-Population statistics); degree of urbanization (CBSPostcode Register). All variables were measured on the first of January 2002, apart from the percentage of non-western migrants which was also measured for 1998 . We used neighbourhood level socio-economic status scores for 1998 and 2002 from the Netherlands Social and Cultural Planning Office (SCP). The scores are based on educational levels, level of unemployment and incomes in neighbourhoods (see SCP, 1998). Detailed variable summary statistics can be found in Table 1.

$$
\text { ---Table_1--- }
$$

The individual-level data (75,043 respondents) were assembled from the 2002 Housing Demand Survey (WBO) of the Ministry of Housing, Spatial Planning and the Environment (VROM), which is available through the Netherlands Scientific Statistical Agency. The research sample was representative of the Netherlands' population aged 18 and over and not living in an institution. The dataset includes the 4-digit postcode of present residence and past residence for those who moved in the two years before the interview. For the analysis, respondents between the ages of 18 and 90 were selected, excluding people still living with their parents, people living in shared housing, people living in non-house accommodations, and people who moved for educational reasons. Further, we excluded people living in the most sparsely populated areas (fewer than 500 addresses per square kilometre). In our analyses we concentrate on out-mobility: people leaving their neighbourhood. We therefore excluded all who moved within the same postal code area in the two years before the interview. Following this selection, the research sample consisted of 47,353 respondents. Detailed variable summary statistics of the individual level data can be found in Table 2 .

$$
\text { ----Table_2---- }
$$

For the neighbourhood level analyses we used linear regression to model a centred logit of the percentage of out-mobility on the postcode level as the dependent variable with mean 0 and having an almost perfect normal distribution. For the individual level analyses we used logistic regression to model whether (1) or not (0) respondents moved to another postcode area in the two years before the interview. Since the models 
included both individual level characteristics and neighbourhood level characteristics and the data included multiple individuals per postcode, the standard errors have been adjusted for clustering of individuals on the postcode level.

\section{ANALYSIS}

\section{Neighbourhood level out-mobility}

In 2002 The Netherlands had a population of approximately 16 million, of which 9.9 percent moved in that year. A small percent (2.3) moved within the same neighbourhood and 7.6 percent moved to another neighbourhood. Figure 1 shows the large variation in out-mobility between neighbourhoods, ranging from zero percent to almost 30 percent. Because in most parts of the Netherlands the housing market is very tight, a high level of out-mobility is an indication of a high level of population turnover, as most vacant dwellings are filled almost immediately. There are hardly any problems in the Netherlands with large-scale abandonment of housing estates, unlike for example, the UK (Parkes and Kearns, 2003). There are several hundred neighbourhoods with an out-mobility of less than 5 percent and at the other extreme there are roughly 100 neighbourhoods with an out-mobility of more than 15 percent, most of which are near or in the four largest cities (Figure 2).

----Figure_1----

----Figure_2---

Table 3 shows the results of regression models of the percentage of out-mobility on the neighbourhood level. In Model 1 several characteristics of the neighbourhood housing stock and population are included. The higher the percentage of homeownership in a neighbourhood, the lower the level of out-mobility. With an increasing percentage of people aged between 15 and 34 the level of out-mobility increases. The level of outmobility decreases with an increasing percentage of people aged between 65 and 84 . Neighbourhoods with a high percentage of households with children have a low level of out-mobility and neighbourhoods with a high level of one-person households have a high level of out-mobility. All these results reflect what we know of mobility on the individual level. The model explains more than 54 percent of all variation in outmobility with a limited set of neighbourhood characteristics.

----Table_3---

Model 2 includes a variable measuring the percentage of non-western ethnic minorities and a variable measuring the change in the percentage of non-western ethnic minorities in the neighbourhood (testing hypotheses 1 and 2). The higher the percentage of ethnic minorities in the neighbourhood, the higher the percentage of out-mobility. The results also show that an increase in the percentage of ethnic minorities between 1998 and the end of 2001 is associated with an increase in the level of out-mobility. These findings are important as the literature demonstrates that those belonging to an ethnic minority group themselves are as likely as or less likely to move than the native population. This could indicate that people leave ethnic concentration neighbourhoods or neighbourhoods experiencing an increase in the percentage of ethnic minorities because of ethnic preferences. The racial proxy hypothesis gives the alternative explanation that the ethnic composition of the neighbourhood is an indication of neighbourhood quality and that neighbourhoods with an increase in ethnic minorities are also neighbourhoods which show a decrease in overall neighbourhood quality. 
Model 3 includes a variable indicating the neighbourhood socio-economic status score and a variable indicating whether a neighbourhood experienced a drop in socioeconomic status between 1998 and the end of 2001 (testing hypotheses 3 and 4). Controlling for the other neighbourhood characteristics, neighbourhoods with a high socio-economic status show a higher level of out-mobility than neighbourhoods with a low socio-economic status. This is the opposite of what we expected, but can be explained by the fact that people with a high income are in general more able and more likely to move. A model with socio-economic status as the only variable shows that postcodes with a low socio-economic status show the highest level of out-mobility (results not shown). Model 3 also shows that neighbourhoods which experience a drop in socio-economic status show a higher level of out-mobility than other neighbourhoods. Since the effect(s) of (changes in) the ethnic composition of the neighbourhood remain roughly the same after controlling for (changes in) the socioeconomic status of the neighbourhood, the results seem not to support the racial proxy hypothesis (hypothesis 6). As mentioned before, Harris (1999) stated that if models properly control for socio-economic composition, neighbourhood desirability should not be affected by ethnic composition.

Finally, in model 4 several spatial characteristics of the neighbourhoods are included. In line with the literature, the results show that with increasing level of urbanization the level of out-mobility increases, except for the most densely populated neighbourhoods. Model 5 also shows that after controlling for all other neighbourhood characteristics, neighbourhoods in the Randstad show the lowest level of out-mobility.

The analysis of out-mobility on the neighbourhood level has yielded some important results. Model 4 explains over $62 \%$ of the total variation in out-mobility with a limited set of explanatory variables. Most of the variation in out-mobility is explained by the composition of the housing stock and the composition of the neighbourhood population. Although the effect of the percentage of owner occupied dwellings in the neighbourhood was not significant in model 4 , a model including only this variable explains 24 percent of all variation in mobility between neighbourhoods (not shown). The fact that this effect disappears once neighbourhood population composition is controlled for implies that neighbourhoods with a high percentage of owner occupied dwellings are neighbourhoods with the least mobile groups.

Our results show that neighbourhoods with a high level of population turnover are mainly neighbourhoods with a very mobile population, and not necessarily bad neighbourhoods. This is in line with findings by Bailey and Livingston (2007) for the UK. An interesting (although not unexpected) finding is that the level of out-mobility increases with the percentage of non-western ethnic minorities in the neighbourhood and is even higher in neighbourhoods which experience an increase in the share of ethnic minorities. The next section on individual level out-mobility will shed more light on this outcome: are the ethnic minorities themselves mobile, do people move because of concentrations of ethnic minorities or is the high level of ethnic minorities in a neighbourhood a proxy for unfavourable neighbourhood characteristics?

\section{Individual level out-mobility}

A series of logistic regression models are used to estimate the probability of leaving the neighbourhood at the individual level (Table 4). Model 1 includes a range of control variables plus two neighbourhood level variables. The control variables all show the expected effect on the probability of moving. With increasing age, the probability of moving decreases; there is no significant gender effect; those belonging to a nonwestern ethnic minority group are less likely to move than others (but this is only the case for renters, see interaction effect); the probability of moving increases with level of education; compared to singles and couples without children, couples with children and lone parents are less likely to move; the probability of moving decreases with the number of rooms available per person in the household; the probability of moving 
increases with household income (but this is only the case for renters, see interaction effect); and homeowners are less likely to move than renters.

----Table_4---

Initially we estimated separate models for homeowners and renters (not shown). The main differences between these two models were the effects of belonging to a nonwestern ethnic minority and the effect of household income. We have therefore included interaction effects between these two variables and the homeowner dummy. The results show that homeowners from non-western ethnic minority groups are more likely to leave their neighbourhood $(-0.379-0.341+0.880=0.160)$ than other homeowners $(-$ $0.341)$, renters from non-western ethnic minority groups $(-0.379)$ and other renters (0). A possible explanation is that ethnic minorities face more restrictions on the housing market than others and can therefore not be too critical about the neighbourhood they choose to live in. But when they move again, they are more likely to leave their neighbourhood as they try to improve their situation. The interaction effect between homeowner and income is negative and significant and indicates that homeowners with a high income $(-0.341+1.052-1.042=-0.331)$ and other homeowners $(-0.341)$ are the least likely to move. Renters in general are most likely to move, especially renters with a high income (1.052).

As hypothesised (hypothesis 1), the percentage of non-western ethnic minorities in the neighbourhood has a positive effect on the probability of moving. Those living in concentration neighbourhoods are most likely to leave the neighbourhood. The effect (0.006) seems small, but for neighbourhoods with the highest percentage of ethnic minorities $(85 \%)$ the effect is relatively high $(0.006 * 85=0.51)$. Also, as expected (hypothesis 2) the change in the percentage in ethnic minorities in the neighbourhood has a positive effect on the probability of moving (0.027).

Two variables are added in Model 2. The results show that people who live in a neighbourhood with a high socio-economic status have a higher probability of moving and leave the neighbourhood than people who live in a neighbourhood with a low socioeconomic status, but the effect is only just significant. In a model without variables measuring the (change in) ethnic composition of the neighbourhood the effect of the socio-economic status variable is negative as expected (not shown). People who live in a neighbourhood where the socio-economic status dropped in recent years are more likely to move (0.140) than people living in neighbourhoods where the socio-economic status increased (hypothesis 4). It is worth noting that for both socio-economic status of the neighbourhood and the ethnic composition of the neighbourhood, the effect of recent change is relatively large compared to the effect of static neighbourhood characteristics. We used several non-linear specifications (including splines) to test for tipping points in the change variables, but did not find clear evidence for tipping points.

In the analyses of neighbourhood level mobility (Table 3) we saw that neighbourhoods with a high percentage of ethnic minorities showed a high level of population turnover. The results in Table 4 show that it is not the ethnic minorities themselves that have a high level of mobility. The only exception is ethnic minority homeowners, but these are a relatively small group. Only 22 percent of non-western ethnic minorities in the dataset are homeowners while 55.6 percent of the others are homeowners.

We also saw a positive effect of the change in the percentage of ethnic minorities in the neighbourhood on mobility. From the literature review we derived the hypothesis (number 5) that an increase in the percentage of non-western ethnic minorities would mainly affect the probability of moving of those not belonging to an ethnic minority. This is tested in Model 3 where an interaction effect between the respondents own ethnicity and the change in ethnic composition of the neighbourhood is included. The results show that the effect of a change of the ethnic composition of the 
neighbourhood is $-0.012(0.029-0.041)$ for ethnic minorities and +0.029 for others. This means that an increase of ethnic minorities in the neighbourhood has a small negative effect on the probability that ethnic minorities move out and a relatively large positive effect for the native Dutch population. The interaction effect between individual income and change in socio-economic status of the neighbourhood is not significant, indicating that the Schelling derived hypothesis is not confirmed for socio-economic status. Since the model also controls for the socio-economic status of the neighbourhood and the change of socio-economic status, the results do not seem to support the racial proxy hypothesis (hypothesis 6).

Finally, in Model 4, dummies for the level of urbanisation and a Randstad dummy are added to the model. Adding these variable changes little compared to Model 3. As expected, the probability of moving increases with the level of urbanisation. After controlling for all other variables, living in the Randstad has no effect on mobility at the individual level.

\section{CONCLUSIONS}

The analyses of out-mobility at the neighbourhood level have shown that the composition of the housing stock and the composition of the neighbourhood population are capable of explaining most variation in mobility between neighbourhoods: neighbourhoods with a high population turnover are simply neighbourhoods with a mobile population. If from a policy point of view high population mobility is regarded as undesirable, there are few options to influence neighbourhood mobility levels. The most effective measure would probably be to increase the level of home ownership in neighbourhoods showing a high level of mobility. By stimulating homeownership it is likely that the neighbourhood population composition shifts towards less mobile groups: older people and households with children.

The neighbourhood level analyses have shown that the level of out-mobility increases with the percentage of non-western ethnic minorities in the neighbourhood and that out-mobility is even higher in neighbourhoods which recently experienced an increase in the level of ethnic minorities. The individual level analyses have shown that it is not the ethnic minority groups themselves who are mobile, ruling out that the neighbourhood level results are simple population composition effects. The individual level analyses show that those living in neighbourhoods with concentrations of ethnic minorities are more likely to move and leave the neighbourhood. Moreover, the analyses also showed that those living in neighbourhoods where there is an increase in the percentage of non-western ethnic minorities are more likely to leave the neighbourhood, but that this is only the case for the native Dutch population.

Our results can be seen as either supporting the preference for own race hypothesis - a Schelling type effect, or some more complex argument involving white flight as a response to a change in racial composition. Unless we argue that the native population 'escapes' neighbourhoods where there is an increase in the concentration of ethnic minorities because of other neighbourhood characteristics, and ethnic minority groups themselves have a 'lower evaluative standards' due to a legacy of discrimination in the housing market (St. John and Clark, 1984), we must conclude that these are responses directly to the change in ethnicity of the neighbourhood population.

Of course, anyone attempting to model the effect of neighbourhood characteristics on mobility behaviour should be aware of the fact that the effects found might be the result of omitted variable bias: unmeasured variables at the individual level or the level of the neighbourhood which correlate with the (change in the) percentage of non-western ethnic minorities in the neighbourhood. For example, neighbourhoods where there is an increase in ethnic minorities might also experience a change in local public services or other amenities associated with the neighbourhood. It might very well 
be that these variables are the 'real' underlying cause of mobility and not the change in ethnic composition. However, since we control for the (change in) socio-economic state of neighbourhoods - the most important control variable mentioned in the literature (see Harris, 1999) - in both our neighbourhood level models and individual level models, it is unlikely that the effect of ethnic composition is simply a proxy for the effect of socioeconomic status of neighbourhoods.

Although the results of the present analyses do not give us an in-depth understanding of the underlying mechanism of the effect of the ethnic composition of neighbourhoods, the results enhance our understanding of processes of segregation and seem to be in line with Schelling's $(1969,1971)$ segregation hypothesis (see also Clark, 1991; Van Ham and Feijten, 2008). The results also cast doubt on the future success of mixed housing strategies as stated explicitly by governments in the Netherlands, the United Kingdom, Germany, France, Finland, and Sweden (Atkinson and Kintrea, 2001; Kearns 2002; Musterd et al., 1999). The idea is that mixing tenures will create mixed ethnic and mixed socio-economic neighbourhoods which will create better social opportunities for individuals (Musterd and Anderson, 2005). However, mixed neighbourhoods will only work when different groups want to live together. With about 10 percent of the Netherlands population moving each year and more than two thirds of these movers leaving their neighbourhood, our results suggest that levels of ethnic segregation are likely to remain high.

\section{Acknowledgements}

Maarten van Ham also contributed to this paper while being a member of the Urban and Regional research centre Utrecht (URU), Faculty of Geosciences, Utrecht University and the OTB Research Institute for Housing, Urban and Mobility Studies, Delft University of Technology. The authors wish to thank the editors of Environment and Planning A and four anonymous referees for their valuable comments.

\section{REFERENCES}

Aitken S C, 1990, "Local evaluations of neighborhood change" Annals Of The Association of American Geographers 80247 - 267

Amérigo M, 2002, "A psychological approach to the study of residential satisfaction", in Residential Environments: Choice, Satisfaction, and Behavior Eds J A Aragonés, G Francescato, T Gärling (Bergin and Garvey, Westport, CT), pp 81 - 99

Andersson R, Bråmå A, 2004, "Selective migration in Swedish distressed neighbourhoods: can area-based urban policies counteract segregation processes?" Housing Studies 19517 - 539

Aneshensel C S, Sucoff C A, 1996, "The neighborhood context of adolescent mental health" Journal of Health and Social Behavior 37293 - 310

Atkinson R, Kintrea K, 2001, "Disentangling area effects: evidence from deprived and non-deprived neighbourhoods" Urban Studies 382277 - 2298

Auletta K, 1982, The Underclass (Random House, New York)

Bailey N, Livingston M, 2007, Population turnover and area deprivation (The Policy Press, Bristol)

Bobo L, Zubrinsky C L, 1996, "Attitudes on residential integration: perceived status differences, mere in-group preference, or racial prejudice?" Social Forces 74883 909

Bolt G, Van Kempen R, 2003, "Escaping poverty neighborhoods in the Netherlands" Housing, theory and society $\mathbf{2 0} 209-222$ 
Bolt G, Van Kempen R, and Van Ham M 2008, "Minority ethnic groups in the Dutch housing market: spatial segregation, relocation dynamics and housing policy" Urban Studies 451359 - 1384

Brower S, 1996 Good Neighbourhoods: A Study of In-town and Suburban Residential Environments (Praeger, Westport, CT)

Brown L A, Moore E G, 1970, "The intra-urban migration process: a perspective" Geografiska Annaler Series B 521 - 13

Brun J, Fagnani J, 1994, "Lifestyles and locational choices - trade-offs and compromises: a case-study of middle-class couples living in the Ile-de-France region" Urban Studies 31921 - 934

Buck N, 2001, "Identifying neighbourhood effects on social exclusion" Urban Studies $382251-2275$

Clark W A V, 1991, "Residential preferences and neighborhood racial segregation - a test of the Schelling segregation model" Demography $281-19$

Clark W A V, 1992, "Residential preferences and residential choices in a multiethnic context" Demography 29451 - 466

Clark W A V, 2007, "Race, Class, and Place, Evaluating Mobility Outcomes, for African Americans" Urban Affairs Review 42295 - 314

Clark W A V, Dieleman F M, 1996 Households and Housing. Choice and Outcomes in the Housing Market (Center for Urban Policy Research, New Brunswick, NJ)

Clark W A V, Deurloo M C, Dieleman F M, 2006 "Residential mobility and neighbourhood outcomes" Housing Studies 21323 - 342

Crowder K, 2000, "The racial context of white mobility: An individual-level assessment of the white flight hypothesis" Social Science Research 29223 - 257

Drukker M, Kaplan C, Van Os J, 2005, "Residential instability in socioeconomically deprived neighbourhoods, good or bad?" Health \& Place 11121 - 129

Duncan G, Brooks-Gunn J, Klebanov P, 1994, "Economic deprivation and early childhood development" Child Development 65296 - 318

Feijten P M, Van Ham M, 2008, "Neighbourhood change... reason to leave?" Submitted to journal; copy available from M Van Ham, School of Geography \& Geosciences, University of St Andrews, UK

Friedrichs J, 1991, "Middle-class leakage in large new housing estates: empirical findings and policy implications" Journal of Architectural and Planning Research $\mathbf{8}$ $287-295$

Friedrichs J, Blasius J, 2003, "Social norms in distressed neighbourhoods: Testing the Wilson hypothesis" Housing Studies 18807 - 826

Galster G C, 1987, Homeowners and neighborhood reinvestment (Duke University Press)

Galster G, 2001, "On the nature of neighbourhood" Urban Studies 382111 - 2124

Gould Ellen I, 2000, "Race-based neighbourhood projection: a proposed framework for understanding new data on racial integration" Urban Studies 371513 - 1533

Harris D R, 1999 “"Property values drop when blacks move in, because...": racial and socioeconomic determinants of neighborhood desirability" American Sociological Review 64461 - 479

Helderman A, Mulder C H, Van Ham M, 2004, The changing effect of home ownership on residential mobility in the Netherlands, 1980-98" Housing Studies $19601-616$

Ihlanfeldt K R, Scafidi B, 2002, "Black self-segregation as a cause of housing segregation: Evidence from the multi-city study of urban inequality" Journal of Urban Economics $\mathbf{5 1}$ 366-390

Ioannides Y M, Zabel J E, 2003, Neighbourhood effects and housing demand, Journal of Applied Econometrics 18 563-584

Katz M B, 1989 The undeserving poor: from the war on poverty to the war on welfare (Pantheon Books, New York) 
Kearns A, 2002, "Response: from residential disadvantage to opportunity? Reflections on British and European policy and research" Housing Studies 17145 - 150

Kearns A, Parkes A, 2003, "Living in and Leaving Poor Neighbourhood Conditions in England" Housing Studies 18827 - 851

Lansdale N S, Guest A M, 1985, "Constraints, satisfaction and residential mobility: Speare's model reconsidered" Demography 22199 - 222

Lee B A, Oropesa R S, Kanan J W, 1994, "Neighborhood context and residentialmobility" Demography 31249 - 270

Moore E G, Clark W A V, 1990, "Housing and households in American cities: structure and change in population mobility, 1974-1982", in Housing demography. Linking demographic structure and housing markets Ed D Myers (Madison, WI: University of Wisconsin Press) pp $203-231$

Mulder C H, 1993 Migration dynamics: a life course approach (Thesis Publishers, Amsterdam)

Musterd S, Anderson R, 2005, "Housing mix, social mix, and social opportunities" Urban Affairs Review 40761 - 790

Musterd S, Ostendorf W, De Vos S, 2003, "Neighbourhood effects and social mobility: a longitudinal analysis" Housing Studies 18877 - 892

Musterd S, Priemus H, Van Kempen R, 1999, "Towards undivided cities: the potential of economic revitalisation and housing redifferentiation" Housing Studies 14573 $-584$

Overman H G, 2002, "Neighbourhood effects in large and small neighbourhoods" Urban Studies 39117 - 130

Page D, 1993 Building for Communities (Joseph Rowntree Foundation, York)

Parkes A, Kearns A, 2003, "Residential perceptions and housing mobility in Scotland: An analysis of the longitudinal Scottish House Condition Survey 1991-96" Housing Studies 18673 - 701

Pawson H, Bramley G, 2000, "Understanding recent trends in residential mobility in council housing in England" Urban Studies 371231 - 1259

Power A, Tunstall R, 1995 Swimming Against the Tide (Joseph Rowntree Foundation, York)

Power A, 1997 Estates on the Edge. The Social Consequences of Mass Housing in Northern Europe (MacMillan, London).

Quigley J M, Weinberg D H, 1977, "Intra-urban residential mobility: A review and synthesis" International Regional Science Review 2 41- 66

Quillian L, 1999, "Migration Patterns and the Growth of High-Poverty Neighborhoods, 1970-1990" American Journal of Sociology 1051 - 37

Quillian L, 2003, "How long are exposures to poor neighborhoods? The long-term dynamics of entry and exit from poor neighborhoods" Population Research and Policy Review 22(3) 221- 249

Rapkin C, Grigsby W, 1960 The Demand for Housing in Racially Mixed Areas (University of California Press, Berkeley, CA)

Sampson R J, Raudenbush S W, Earls F, 1997, "Neighborhoods and violent crime: a multilevel study of collective efficacy" Science $277918-924$

Schelling T C, 1969, "Models of segregation" The American Economic Review 59488 493

Schelling T C, 1971, "Dynamic models of segregation" Journal of mathematical sociology 1 143-186.

SCP, 1998 Van hoog naar laag; van laag naar hoog.[down and up; up and down] Cahier nr. 152 (Sociaal en Cultureel Planbureau, Rijswijk)

Shaw C R, McKay H, 1969, Juvenile Delinquency and Urban Areas: A Study of Rates of Delinquency in Relation to Differential Characteristics of Local Communities in American Cities, revised edition (University of Chicago Press, Chicago) 
Skifter Andersen H, 2002 Urban Sores: On the Interaction between Segregation, Urban Decay and Deprived Neighbourhoods (Ashgate, Aldershot)

Social Exclusion Unit (2001) A New Commitment to Neighbourhood RenewalNational Strategy Action Plan (Cabinet Office, London)

Speare A, Goldstein S, Frey W H, 1975 Residential mobility, migration, and metropolitan change (Ballinger, Cambridge Mass)

St. John C, Clark F, 1984, "Racial differences in dimensions of neighborhood satisfaction" Social Indicators Research 1543 - 60

Talen E, 2001, "Traditional urbanism meets residential affluence: an analysis of the variability of suburban preference" Journal of the American Planning Association $67199-216$

Taub R P, Taylor G D, Dunham J D, 1984 Paths of Neighborhood Change (University of Chicago Press, Chicago, IL)

Van der Klaauw B, Van Ours J C, 2003, "From welfare to work: does the neighborhood matter?" Journal Of Public Economics 87957 - 985

Van Ham M, Feijten P M, 2008, "Who wants to leave the neighbourhood? The effect on moving wishes of being different from the neighbourhood population" Environment and Planning A 401151 - 1170

Wilson W, 1987 The truly disadvantaged. The inner city, the underclass and public policy (University of Chicago Press, Chicago)

Wolf E P, 1963, "The tipping-point and racially changing neighborhoods" Journal of the American Institute of Planners 29217 - 222

Zorlu A, Mulder C H, 2008, "Initial and subsequent location choices of immigrants to the Netherlands" Regional Studies 42245 - 264 
Table 1. Variable summary statistics postcode data $(\mathrm{N}=2,604)$

\begin{tabular}{|c|c|c|c|c|}
\hline & Minimum & Maximum & Mean & Std. Dev. \\
\hline Percentage out-mobility & 0.00 & 28.32 & 7.536 & 3.731 \\
\hline Logit percentage out mob. (dependent) & -18.97 & 18.89 & 0.000 & 5.096 \\
\hline$\%$ Owner occupied & 2.90 & 100.00 & 60.222 & 19.064 \\
\hline$\%$ Aged $15-34$ & 3.30 & 86.40 & 25.835 & 6.505 \\
\hline$\%$ Aged $65-84$ & 0.00 & 63.90 & 12.152 & 5.162 \\
\hline$\%$ Households with children & 2.10 & 75.00 & 39.331 & 11.029 \\
\hline$\%$ One-person households & 0.00 & 94.00 & 29.250 & 13.065 \\
\hline$\%$ Non-western ethnic minorities 2002 & 0.00 & 85.01 & 7.371 & 10.461 \\
\hline Change $\%$ non-western ethn $\min 98-01$ & -10.75 & 32.16 & 1.550 & 2.628 \\
\hline Socio-Econ. Status score $2002^{1}$ & -4.55 & 3.32 & 0.014 & 1.028 \\
\hline Drop in S-E Status score 1998-2001 & 4.07 & -4.26 & 0.040 & 0.539 \\
\hline \% Dwellings built after 1991 & 0.00 & 100.00 & 15.551 & 16.748 \\
\hline \multicolumn{5}{|l|}{ Urbanization (ref=Weakly urban) } \\
\hline Urbanized & 0 & 1 & 0.245 & \\
\hline Strongly urbanized & 0 & 1 & 0.257 & \\
\hline Very strongly urbanized & 0 & 1 & 0.134 & \\
\hline In Randstad (ref=not Randstad) & 0 & 1 & 0.342 & \\
\hline
\end{tabular}

Table 2. Variable summary statistics WBO data $(\mathrm{N}=47,353)$

\begin{tabular}{|c|c|c|c|c|}
\hline & Minimum & Maximum & Mean & Std. Dev. \\
\hline Move out of neighbourhood (dependent) & 0 & 1 & 0.100 & \\
\hline \multicolumn{5}{|l|}{ Individual and household level variables } \\
\hline Age in years & 18 & 90 & 48.967 & 0.074 \\
\hline Male $($ reference $=$ female $)$ & 0 & 1 & 0.456 & \\
\hline Non-Western ethnic minority (reference $=$ other) & 0 & 1 & 0.077 & \\
\hline \multicolumn{5}{|l|}{ Educational level (reference = primary educ) } \\
\hline Lower secondary education & 0 & 1 & 0.173 & \\
\hline Upper secondary education & 0 & 1 & 0.148 & \\
\hline Higher vocational education & 0 & 1 & 0.288 & \\
\hline University education & 0 & 1 & 0.265 & \\
\hline \multicolumn{5}{|l|}{ Household type $($ reference $=$ single $)$} \\
\hline Couple, no kids & 0 & 1 & 0.315 & \\
\hline Couple with kids & 0 & 1 & 0.327 & \\
\hline Lone parent households & 0 & 1 & 0.057 & \\
\hline Other households & 0 & 1 & 0.024 & \\
\hline Rooms per person & 0.29 & 10.00 & 2.201 & 0.005 \\
\hline High household income ( $10 \%$ highest incomes) & 0 & 1 & 0.100 & \\
\hline Homeowner (reference $=$ renter $)$ & 0 & 1 & 0.531 & \\
\hline \multicolumn{5}{|l|}{ Neighbourhood level variables } \\
\hline$\%$ Non-western ethnic minorities neighbh 2002 & 0.00 & 85.01 & 11.675 & 0.058 \\
\hline Change \% non-western ethnic min 1998-2001 & -10.75 & 32.16 & 2.304 & 0.012 \\
\hline Socio-Econ. Status score neighbourhood 2002 & -4.55 & 3.22 & 0.216 & 0.005 \\
\hline Drop in S-E status score neighbh 1998-2001 & 3.97 & -2.51 & 0.094 & 0.378 \\
\hline \multicolumn{5}{|l|}{ Urbanization (reference = Weakly urbanized) } \\
\hline Urbanized & 0 & 1 & 0.246 & \\
\hline Strongly urbanized & 0 & 1 & 0.304 & \\
\hline Very strongly urbanized & 0 & 1 & 0.242 & \\
\hline Postcode in Randstad (reference $=$ not Randstad) & 0 & 1 & 0.460 & \\
\hline
\end{tabular}


Figure 1. Distribution of postcodes by percentage of out-mobility, 2002.

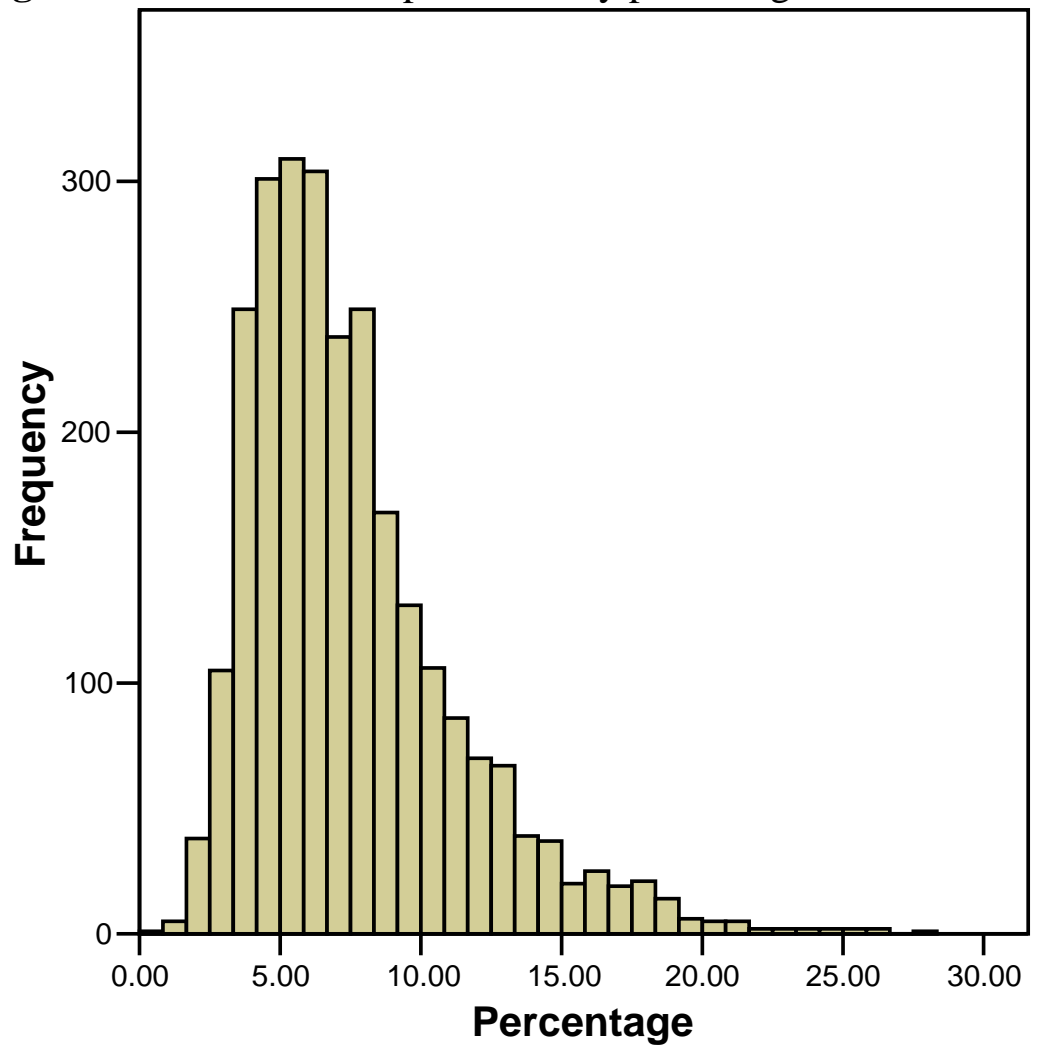

Source: CBS (own calculations)

Figure 2. Map of Randstad with percentage of out-mobility per postcode, 2002.

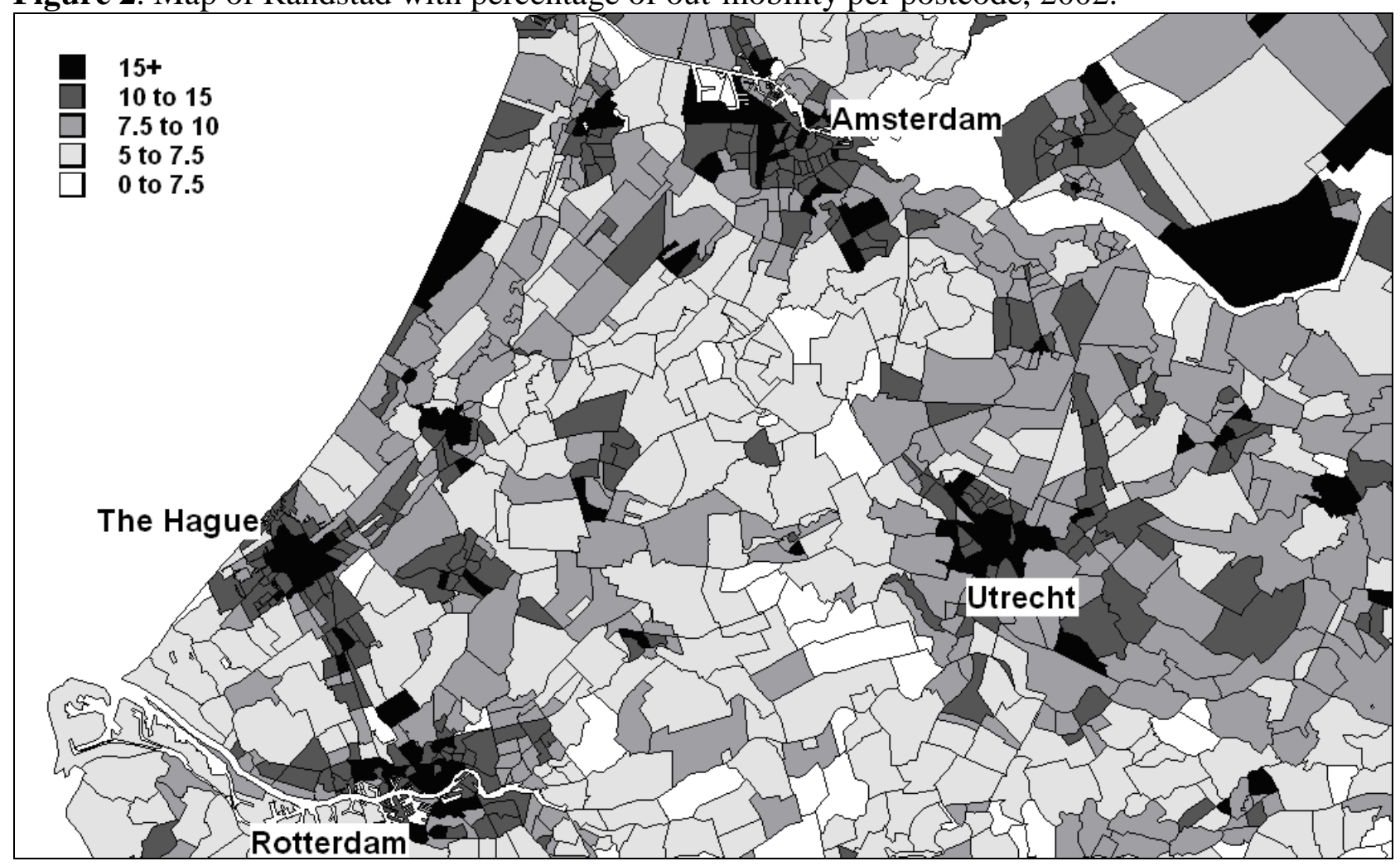

Source: CBS (own calculations) 
Table 3. Regression model of percentage out-mobility on neighbourhood level $(\mathrm{N}=2,604)$

\begin{tabular}{|c|c|c|c|c|c|c|c|c|c|c|c|c|}
\hline & \multicolumn{3}{|c|}{ Model 1} & \multicolumn{3}{|c|}{ Model 2} & \multicolumn{3}{|c|}{ Model 3} & \multicolumn{3}{|c|}{ Model 4} \\
\hline & $\mathrm{B}$ & Beta & & $\mathrm{B}$ & Beta & & $\mathrm{B}$ & Beta & & $\mathrm{B}$ & Beta & \\
\hline$\%$ Owner occupied 2002 & -0.030 & -0.111 & $* * *$ & -0.004 & -0.016 & & -0.017 & -0.062 & $* * *$ & 0.002 & 0.009 & \\
\hline$\%$ Aged 15-34 2002 & 0.053 & 0.068 & $* * *$ & 0.056 & 0.071 & $* * *$ & 0.123 & 0.155 & $* * *$ & 0.107 & 0.135 & $* * *$ \\
\hline$\%$ Aged 65-84 2002 & -0.245 & -0.248 & $* * *$ & -0.220 & -0.221 & $* * *$ & -0.157 & -0.158 & $* * *$ & -0.156 & -0.156 & $* * *$ \\
\hline$\%$ Households with children 2002 & -0.085 & -0.185 & $* * *$ & -0.129 & -0.279 & $* * *$ & -0.119 & -0.257 & $* * *$ & -0.099 & -0.213 & $* * *$ \\
\hline$\%$ One-person households 2002 & 0.193 & 0.495 & $* * *$ & 0.141 & 0.361 & $* * *$ & 0.129 & 0.329 & $* * *$ & 0.131 & 0.335 & $* * *$ \\
\hline$\%$ Non-western ethnic minorities 2002 & & & & 0.067 & 0.137 & $* * *$ & 0.101 & 0.207 & $* * *$ & 0.113 & 0.233 & $* * *$ \\
\hline Change $\%$ non-west eth min $98-01$ & & & & 0.159 & 0.082 & $* * *$ & 0.113 & 0.058 & $* * *$ & 0.086 & 0.044 & $* * *$ \\
\hline Socio-Econ. Status score 2002 & & & & & & & 0.848 & 0.170 & $* * *$ & 0.785 & 0.158 & $* * *$ \\
\hline Drop in S-E Status score 98-01 & & & & & & & 0.503 & -0.052 & $* * *$ & 0.399 & -0.041 & $* * *$ \\
\hline$\%$ Dwellings built after 1991 & & & & & & & & & & -0.019 & -0.056 & $* * *$ \\
\hline \multicolumn{13}{|l|}{ Urbanization (ref=Weakly urban) } \\
\hline Urbanized & & & & & & & & & & 1.644 & 0.139 & $* * *$ \\
\hline Strongly urbanized & & & & & & & & & & 2.711 & 0.233 & $* * *$ \\
\hline Very strongly urbanized & & & & & & & & & & 1.998 & 0.133 & $* * *$ \\
\hline In Randstad (ref=not Randstad) & & & & & & & & & & -1.251 & -0.117 & $* * *$ \\
\hline Constant & 2.098 & & & 2.708 & & $* *$ & 0.709 & & & -1.615 & & \\
\hline Adjusted R Square & 0.542 & & & 0.570 & & & 0.585 & & & 0.624 & & \\
\hline $\mathrm{F}(\mathrm{df})$, sig & $623(5), 0$ & 000 & & $495(7), 0$ & 000 & & $408(9), 0$ & .000 & & $309(14),($ & .000 & \\
\hline Res Sum of Squares (total 67651) & 31177 & & & 28999 & & & 28009 & & & 25290 & & \\
\hline$*=\mathrm{p}<0.10 ; * *=\mathrm{p}<0.05 ; * * *=\mathrm{p}<0.01$ & & & & & & & & & & & & \\
\hline
\end{tabular}


Table 4. Logistic regression model of leaving the neighbourhood on individual level $(\mathrm{N}=47,353)$

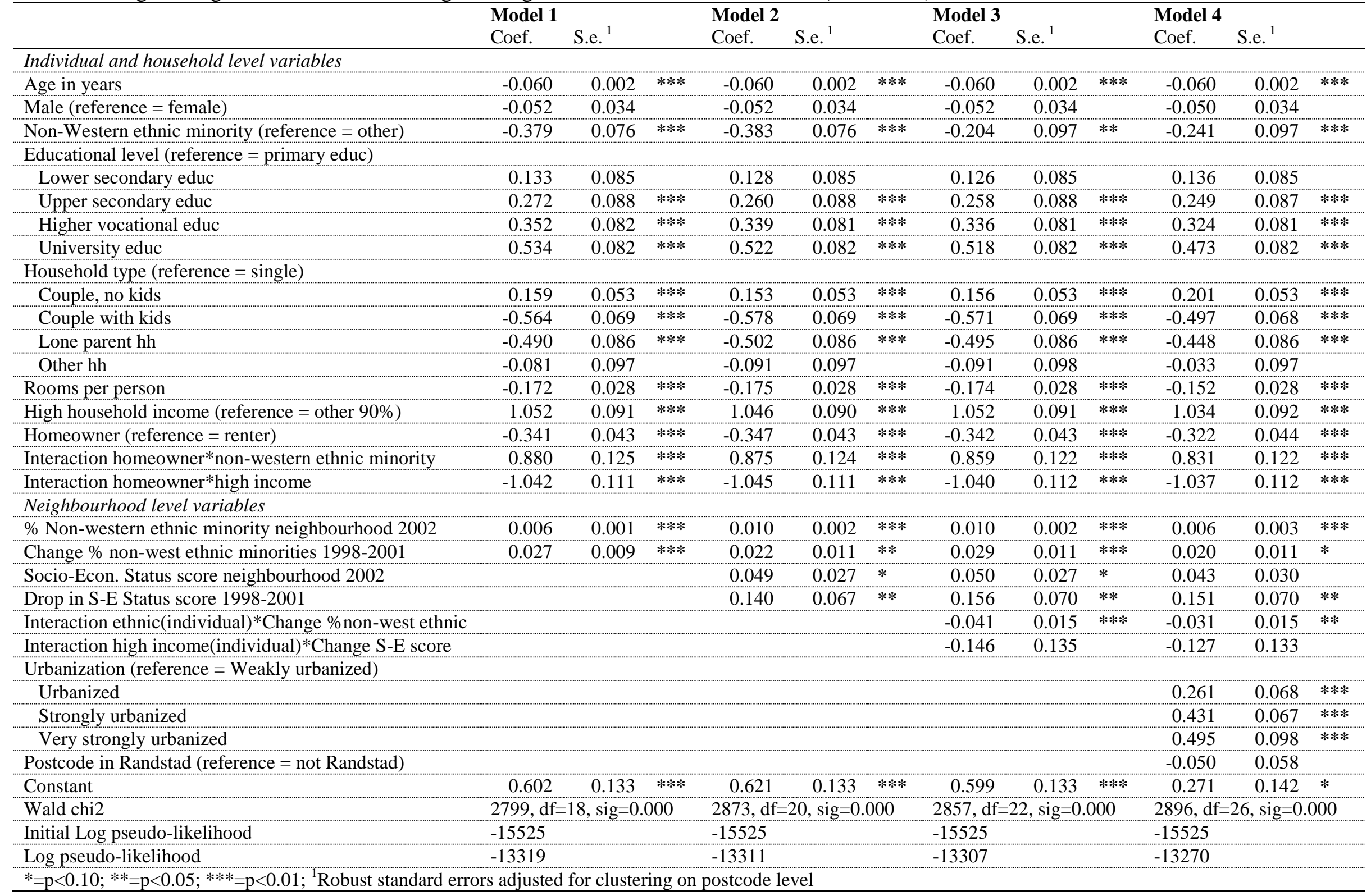

